\title{
Influência hipsométrica na fragmentação em regiões semiáridas
}

\author{
Jéssica Stéfane Alves CUNHA ${ }^{1 *}$, Ana Lícia Patriota FELICIANO ${ }^{1}$, Emanuel Araújo SILVA ${ }^{2}$, \\ Luiz Carlos MARANGON ${ }^{1}$, Fabiana ESTIGARRIBIA
}

${ }^{1}$ Programa de Pós-Graduação em Ciências Florestais, Universidade Federal Rural do Pernambuco, Recife, PE, Brasil. *E-mail: cunhajsa@gmail.com

Recebido em fevereiro/2018; Aceito em abril/2018.

\begin{abstract}
RESUMO: A degradação da floresta nativa, em regiões secas, encontra-se em expansão devido a exploração da madeira e à conversão da vegetação em distintos usos. Assim, objetivou-se analisar a fragmentação da paisagem em áreas semiáridas e a influência do gradiente altitudinal nesse processo. Para tanto, as imagens RapidEye adquiridas no ano de 2014 foram segmentadas, identificadas e classificadas em Floresta e Outros usos, bem como confeccionados mapas categóricos para utilizar no software Fragstats e gerar dados para análise das métricas da paisagem. Os resultados dos parâmetros determinaram que as regiões secas possuem uma alta quantidade de fragmentos menores que cinco ha demonstrando um alto retalhamento. $\mathrm{O}$ ambiente Baixada é o mais prejudicado, diante da maior quantidade de fragmentos menores e da distância entre os mesmos, isso é devido a cobertura florestal desse ambiente está sob pressão sendo mais vulnerável à fragmentação, em virtude do cultivo agrícola e pastagem. De forma oposta se encontra o ambiente Chapada, no qual a classe Floresta comporta-se como a matriz da paisagem. Portanto, a altitude influencia o processo de fragmentação da vegetação nativa de regiões semiáridas, uma vez que ao aumentar a altitude também aumenta a conectividade entre os fragmentos.
\end{abstract}

Palavras-chave: Análise da paisagem, métricas, Brasil, gradiente, fragstats.

\section{Hypsometric influence in fragmentation in semi-arid regions}

\begin{abstract}
The degradation of native forest, in dry regions, is expanding due to the exploitation of wood and the conversion of vegetation to different uses. Thus, the objective was to analyze the fragmentation of the landscape in semi-arid areas and the influence of the altitudinal gradient in this process. To do so, the RapidEye images acquired in the year of 2014 were segmented, identified and classified in Forest and Other uses, and also categorical maps were made to be used in the Fragstats software and generate data for analysis of the landscape metrics. The results of the parameters determined that the dry regions have a high amount of fragments smaller than five, demonstrating a high shredding. The Lowland environment is the most affected, due to the greater amount of smaller fragments and the distance between them, this is due to the forest cover of this environment is under pressure being more vulnerable to fragmentation, due to the agricultural cultivation and pasture. On the opposite side is the Plateau environment, in which the Forest class behaves as the matrix of the landscape. Therefore, altitude influences the fragmentation process of native vegetation of semiarid regions, since increasing the altitude also increases the connectivity between the fragments.
\end{abstract}

Keywords: Landscape analysis, metrics, Brazil, gradient, fragstats.

\section{INTRODUÇÃO}

Com a intensidade das ações antrópicas no meio ambiente, encadeia-se um processo de fragmentação das paisagens naturais por outros usos e ocupações do solo. Tornando perceptível a supressão florestal para a expansão pecuária e agrícola. Tais alterações transformam áreas florestais extensas e contínuas, em fragmentos, afetando a disponibilidade e a qualidade dos recursos naturais.

As regiões semiáridas são definidas pelo desequilíbrio entre oferta e demanda desses recursos naturais e esse descompasso é exercido pelo uso inadequado da terra, ocasionando perda de diversidade biológica e afetando a estrutura do ecossistema (BRASIL, 2004; SÁ et al., 2010).

As explorações desses recursos naturais podem induzir à degradação ambiental e a aceleração dessa degradação depende da fragilidade natural do ambiente. Portanto, essas ações exploratórias como fonte de geração de energia, são elementos atuantes no isolamento e fragmentação da paisagem com predomínio de extensas áreas de cultivos agrícolas.
Diante disso, a análise e interpretação da estrutura da paisagem são os primeiros passos para compreender, espacialmente, de forma macro a região e gerar informações para futuras pesquisas e intervenções. Dessa maneira, a ecologia da paisagem apresenta alternativas eficazes para resolver problemas ambientais, em razão de resolvê-los em uma perspectiva que considera as interações espaciais entre unidades culturais e naturais, incluindo, assim, o homem no sistema de análise (METZGER, 2001).

Assim, devido a necessidade de examinar padrões e processos ecológicos para solucionar esses problemas ambientais foram desenvolvidos diversos índices para caracterizar as paisagens naturais. Esses índices permitem a quantificação da estrutura e padrões espaciais, o que torna fundamental o uso dessas métricas nas análises de paisagens naturais (MCGARIGAL; MARKS, 1995). Mediante as técnicas de Sistemas de Informações Geográficas - SIG determina-se esses índices espaciais especificando a homogeneidade ou fragmentação da paisagem (SOUZA et al., 
2014). À vista disso, o objetivo desse trabalho é analisar a relação da altitude no processo de fragmentação em regiões semiáridas no Brasil.

\section{MATERIAL E MÉTODOS}

2.1. Localização e caracterização das áreas de estudo

O trabalho foi desenvolvido na região do Araripe, domínio da Bacia do Rio Brígida, Pernambuco, Brasil. A região possui a semiaridez acentuada na parte mais baixa e aumento das precipitações na parte correspondente à Chapada do Araripe (LOPES, 2005).

As paisagens analisadas apresentaram diferentes dimensões, devido ao fato de terem sido pré-definidas para futuras pesquisas. Desta forma, para o mapeamento e análise da paisagem foi executado o buffer com distância de $2,5 \mathrm{~km}$, de cada área, evitando a sobreposição onde as paisagens compostas por cada área e seus respectivos buffers foram analisados. A amostragem foi realizada em três ambientes com diferentes altitudes, sendo o ambiente de Baixada com altitude de até 600 m, o ambiente Encosta com alturas entre 600 e 750 me o ambiente Chapada com altitudes acima de $750 \mathrm{~m}$. A amostragem total foi em nove áreas, sendo três em cada ambiente e localizadas nos municípios de Araripina, Ipubi e Exú (Figura 1).

Tabela 1. Relação das áreas de estudo em regiões semiáridas no Brasil

Table 1. List of study areas in semi-arid regions in Brazil.

\begin{tabular}{ccc}
\hline Ambiente & Nomenclatura & Município \\
\hline \multirow{3}{*}{ Baixada } & Área 1 (B1) & Araripina \\
& Área 2 (B2) & Araripina \\
& Área 3 (B3) & Araripina \\
\hline \multirow{3}{*}{ Encosta } & Área 1 (E1) & Araripina \\
& Área 2 (E2) & Araripina \\
& Área 3 (E3) & Araripina \\
\hline \multirow{3}{*}{ Chapada } & Área 1 (C1) & Araripina \\
& Área 2 (C2) & Ipubi \\
& Área 3 (C3) & Exú \\
\hline
\end{tabular}

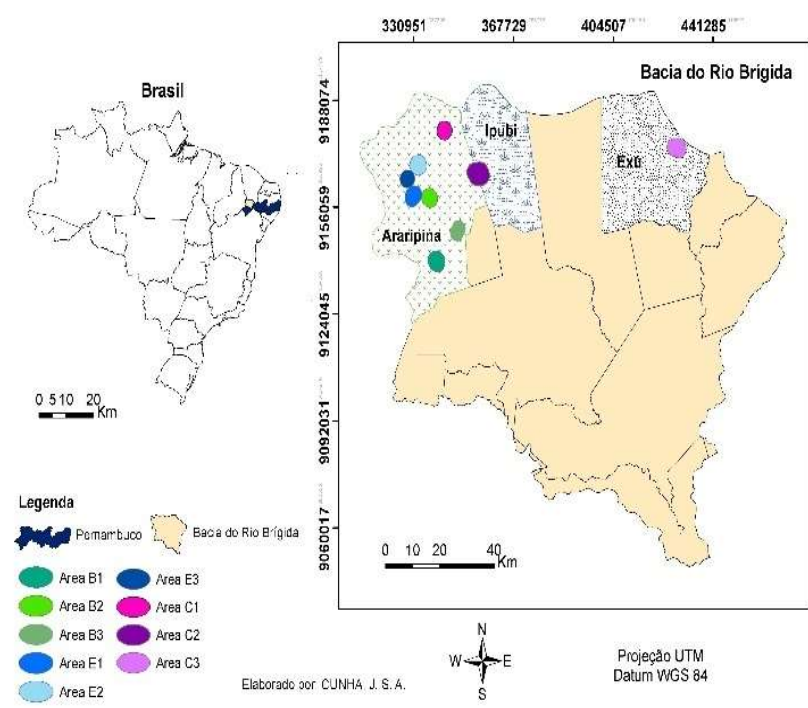

Figura 1. Localização das áreas de estudos em regiões secas no Brasil.

Figure 1. Location of study areas in the dry region in Brazil. 2.2 Base de dados
Inicialmente, foram adquiridas imagens RapidEye com as cenas abrangendo a região de estudo (Tabela 2). As cenas foram cedidas pelo Governo Federal distribuídas no GeoCatálogo do Ministério do Meio Ambiente (MMA, 2016) e ortorretificadas (nível 3A) com tamanho de pixel no terreno de 5 (cinco) metros.

Tabela 2. Cenas das imagens RapidEye obtidas pelo MMA (Ministério do Meio Ambiente) para a região semiárida no Brasil.

Table 2. Scenes from the RapidEye images obtained by the MMA (Ministry of the Environment) for the semi-arid region in Brazil

\begin{tabular}{ccc}
\hline IMAGEM & CENA & DATA \\
\hline & 2435508 & $05 / 08 / 2014$ \\
& 2435607 & $04 / 06 / 2014$ \\
RAPIDEYE & 2435608 & $05 / 08 / 2014$ \\
& 2435609 & $31 / 07 / 2014$ \\
& 2435611 & $31 / 07 / 2014$ \\
& 2435612 & $26 / 05 / 2014$ \\
& 2435507 & $22 / 07 / 2015$ \\
\hline
\end{tabular}

\subsection{Processamento digital das imagens}

O processamento das imagens digitais, a vetorização de mapas temáticos e a interpretação visual foram realizados no software ArcGis 10.2.1. (ESRI, 2014). As imagens foram importadas para realizar o mosaico e recorte dos buffers, compreendendo uma distância de 2,5 (dois e meio) $\mathrm{km}$. As imagens foram analisadas pela composição de cores (R5G3B2) das bandas, juntamente com o aprimoramento do contraste e pelas observações de campo. Foram constatadas a presença de vegetação densa (formações florestais arbóreas) e esparsa (vegetação arbustiva e arbustivo-arbórea) identificadas nessa pesquisa como a classe Floresta e; como a classe Outros usos a agropecuária, solo exposto, corpos d'água, urbano, nuvem e sombra. Após definido os padrões das classes, foi realizado o treinamento das amostras para o reconhecimento espectral da classe, sendo as imagens submetidas à classificação supervisionada por Máxima Verossimilhança. Foram confeccionados os mapas temáticos para as noves áreas localizadas na região do Araripe - PE e a confiabilidade da classificação digital das áreas de estudo foi realizada pela matriz de confusão e classificadas aplicando-se o coeficiente de Kappa (COHEN, 1960) variando de -1 a 1 (Tabela 3)

Tabela 3. Qualidade da classificação do uso e cobertura da terra segundo intervalos do coeficiente Kappa.

Table 3. Quality of use classification and land cover according to Kappa coefficient intervals.

\begin{tabular}{cc}
\hline Valor do Kappa & Qualidade da classificação \\
\hline$<0,00$ & Péssima \\
$0,0-0,20$ & Ruim \\
$0,20-0,40$ & Razoável \\
$0,40-0,60$ & Boa \\
$0,60-0,80$ & Muito Boa \\
$0,80-1,00$ & Excelente \\
\hline
\end{tabular}

Fonte: Landis; Koch (1977).

2.4. Preparação e cálculos dos dados para a análise da paisagem e métricas utilizadas

A análise dos padrões espaciais foi realizada por imagens, em formato raster (.TIF) pelo software Fragstats ${ }^{\circledR}$ versão 4.2 (MCGARIGAL, 2015), a partir dos arquivos dos mapas categóricos de Floresta (e Outros Usos, foram gerados arquivos texto pelo Fragstats para os cálculos das métricas de 
nível classe e das métricas de toda a paisagem e, posteriormente, analisados.

Para os dados das métricas da paisagem foram selecionados índices que quantificaram os elementos da paisagem, estimando a área e a proximidade. As métricas selecionadas, com base em McGarigal; Marks (1995):

I. Métricas de área: fornecem as dimensões dos fragmentos e a quantidade por unidade de área de paisagem. Em nível de fragmento foram calculados o número de fragmentos (NP), em nível de classe a área de cada classe (CA) e em nível de paisagem a porcentagem de fragmentos de mesma classe na paisagem (PLAND).

II. Métricas de proximidade: foi avaliado o índice da distância do vizinho mais próximo (distância entre fragmentos do mesmo tipo de classe, nesse estudo a classe Floresta) (ENN_MN e ENN_CV).

\section{RESULTADOS}

A matriz de erro ou de confusão foi usada para determinar a exatidão para as categorias Floresta e de Outros usos apresentadas nos três ambientes. Para os valores do índice de Kappa obtidos no ambiente de Baixada de 0,95, 0,91 e 0,91 das áreas B1, B2 e B3 respectivamente, constatou-se que a qualidade da classificação para o uso e cobertura da terra foi considerada excelente de acordo com a escala $(0,80-1,00)$ proposta por Landis e Koch (1977). O ambiente Encosta foi qualificado com excelente classificação, em razão dos resultados dos índices nas áreas E1, E2 e E3 foi de 0,84, 0,82 e 0,94. As áreas C1, C2 e C3 inseridas no ambiente Chapada demostraram valores dos índices de $0,89,0,91$ e 0,83 nessa ordem, sendo consideradas de excelente qualidade na classificação do uso e cobertura da terra.

Pelas análises das métricas de paisagem foi avaliado o grau de fragmentação da vegetação natural (Tabela 4). Os parâmetros determinam que os ambientes mais atingidos e fragmentados foram os ambientes Baixada e Encosta, em virtude da cobertura florestal desses ambientes está sob forte pressão, deixando mais susceptíveis à fragmentação e as influências externas (Figura 2 e 3). Entretanto, esses parâmetros permitem afirmar que no ambiente Chapada (Figura 4) a Floresta comporta-se como a matriz da paisagem, devido aos valores do número de fragmentos (NP), a área ocupada (CA) e a porcentagem na paisagem (PLAND), bem como a distância média do vizinho mais próximo (ENN_MN).

A vegetação nas três áreas do ambiente Baixada estão distribuídas em 96,04\% (278 NP) para a área B1, 96,32\% (299 $\mathrm{NP})$ para a área B2 e 96,36\% (247 NP) para a B3, demonstrando que a maioria dos remanescentes possuem áreas menores que 5 (cinco) ha.

Para o ambiente Encosta contabilizaram-se 381 (95,54\%) fragmentos florestais para a área E1; 109 (97,25\%) para a área E2 e $343(95,04 \%)$ fragmentos florestais na área E3. Nas três áreas retratadas verifica-se a prevalência de fragmentos, de floresta nativa, menores que 5 (cinco) ha.

A análise da quantidade de fragmentos para as áreas do ambiente Chapada resultou em 74 (94,59\%) fragmentos florestais para a área $\mathrm{C} 1 ; 148(98,65 \%)$ para a área C2 e 152 $(96,05 \%)$ na área C3, destacando-se o predomínio de fragmentos florestais com tamanhos menores que 5 (cinco) ha.

Tabela 4. Distribuição dos fragmentos de floresta nativa nas classes de área dos ambientes Baixada, Encosta e Chapada em regiões semiáridas no Brasil.

Table 4. Distribution of native forest fragments in the lower, Hill and Plateau area classes in semi-arid regions in Brazil.

\begin{tabular}{|c|c|c|c|c|c|c|c|c|c|}
\hline \multicolumn{10}{|c|}{ Número de fragmentos (NP) Área - Percentual } \\
\hline Classes de tamanhos & B1 & $\%$ & $\begin{array}{c}\% \text { de ocupação na } \\
\text { paisagem }\end{array}$ & B2 & $\%$ & $\begin{array}{c}\text { \% de ocupação na } \\
\text { paisagem }\end{array}$ & B3 & $\%$ & $\begin{array}{c}\% \text { de ocupação na } \\
\text { paisagem }\end{array}$ \\
\hline Pequeno $(<5$ ha $)$ & 267 & 96,04 & 7,54 & 288 & 96,32 & 6,11 & 238 & 96,36 & 0,39 \\
\hline Médio (5 - 50 ha) & 9 & 3,24 & 8,85 & 9 & 3,01 & 9,73 & 7 & 2,38 & 6,97 \\
\hline Grande $(>50 \mathrm{ha}$ & 2 & 0,72 & 83,61 & 2 & 0,67 & 84,16 & 2 & 0,81 & 89,1 \\
\hline Todos $(0 \mathrm{a}>50 \mathrm{ha})$ & 278 & 100 & 100 & 299 & 100 & 100 & 247 & 100 & 100 \\
\hline Classes de tamanhos & E1 & $\%$ & $\begin{array}{c}\text { \% de ocupação na } \\
\text { paisagem }\end{array}$ & E2 & $\%$ & $\begin{array}{c}\text { \% de ocupação na } \\
\text { paisagem }\end{array}$ & E3 & $\%$ & $\begin{array}{c}\% \text { de ocupação na } \\
\text { paisagem }\end{array}$ \\
\hline Pequeno $(<5$ ha $)$ & 364 & 95,54 & 6,79 & 106 & 97,25 & 1,38 & 326 & 95,04 & 8,99 \\
\hline Médio (5 - 50 ha) & 14 & 3,67 & 17,27 & 2 & 1,83 & 0,58 & 14 & 4,08 & 16 \\
\hline Grande ( $>50 \mathrm{ha}$ & 3 & 0,79 & 75,94 & 1 & 0,92 & 98,05 & 3 & 0,87 & 75,01 \\
\hline Todos $(0 \mathrm{a}>50 \mathrm{ha})$ & 381 & 100 & 100 & 109 & 100 & 100 & 343 & 100 & 100 \\
\hline Classes de tamanhos & $\mathrm{C} 1$ & $\%$ & $\begin{array}{c}\text { \% de ocupação na } \\
\text { paisagem }\end{array}$ & $\mathrm{C} 2$ & $\%$ & $\begin{array}{c}\text { \% de ocupação na } \\
\text { paisagem }\end{array}$ & $\mathrm{C} 3$ & $\%$ & $\begin{array}{c}\% \text { de ocupação na } \\
\text { paisagem }\end{array}$ \\
\hline Pequeno (<5ha) & 70 & 94,59 & 1,31 & 146 & 98,65 & 0,42 & 146 & 96,05 & 1,28 \\
\hline Médio (5 - 50 ha) & 3 & 4,05 & 2,07 & 1 & 0,68 & 0,33 & 3 & 1,97 & 2,93 \\
\hline Grande ( $>50$ ha & 1 & 1,35 & 96,62 & 1 & 0,68 & 99,25 & 3 & 1,97 & 95,79 \\
\hline Todos $(0 \mathrm{a}>50 \mathrm{ha})$ & 74 & 100 & 100 & 148 & 100 & 100 & 152 & 100 & 100 \\
\hline
\end{tabular}

B1 - área 1 do ambiente Baixada; B2 - área 2 do ambiente Baixada; B3 - área 3 do ambiente Baixada; E1 - - área 1 do ambiente Encosta; E2 - área 2 do ambiente Encosta; E3 - área 3 do ambiente Encosta; C1 - área 1 do ambiente Chapada; C2 - área 2 do ambiente Chapada; C3 - área 3 do ambiente Chapada.

A paisagem é influenciada pela quantidade de fragmentos (NP), entretanto os dados dessa métrica não demonstram o estádio representativo da região. Assim, a métrica de número de fragmentos (NP) deve ser analisada, juntamente, com as métricas de área total da classe (CA) e a porcentagem na paisagem (PLAND) para se ter uma compreensão efetiva das áreas em estudo. Portanto, a área B1 no ambiente Baixada com $36,40 \%$ (1125,93 ha) de Floresta na paisagem; as áreas E2 e
E3 no ambiente Encosta com 50,16\% (1505,63 ha) 48,32\% (1095,80 ha), respectivamente e; a área C3 no ambiente Chapada com 78,17\% (2573,88 ha) são as áreas indicadas como as mais fragmentadas de cada ambiente (Tabela 5), respaldando, esse fato, pelos valores da métrica de distância média do vizinho, a qual demonstra que as áreas indicadas como as mais fragmentadas possuem maior distância entre fragmentos. 


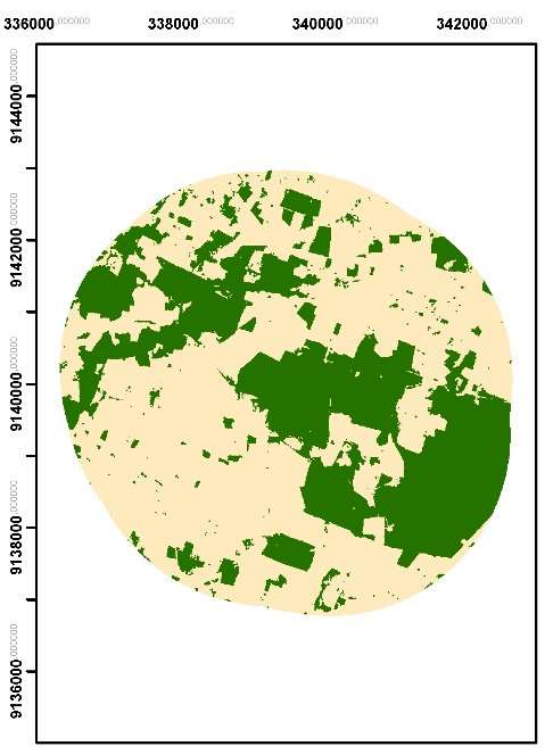

Área B1- 3093,06 ha

Floresta - 1125,93 ha

Outros usos - 1967,13 ha

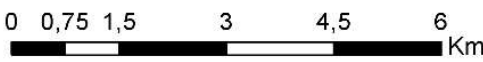

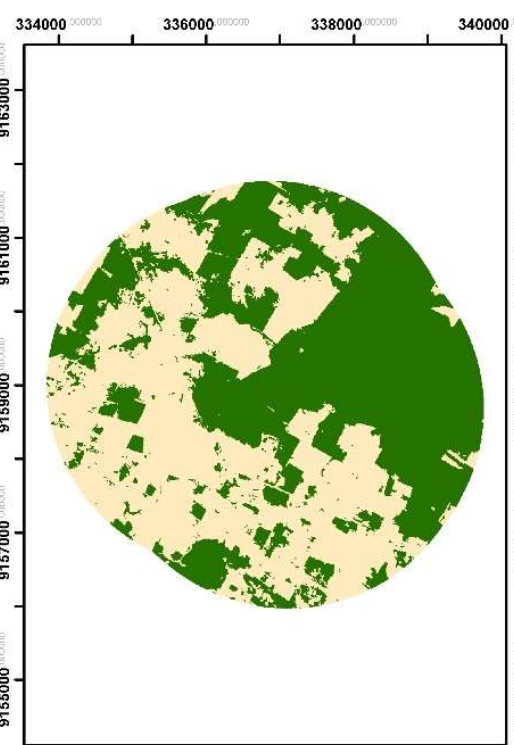

Área B2 - 2625,85 ha

Floresta - 1329,06 ha

Outros usos - 1296,78 ha

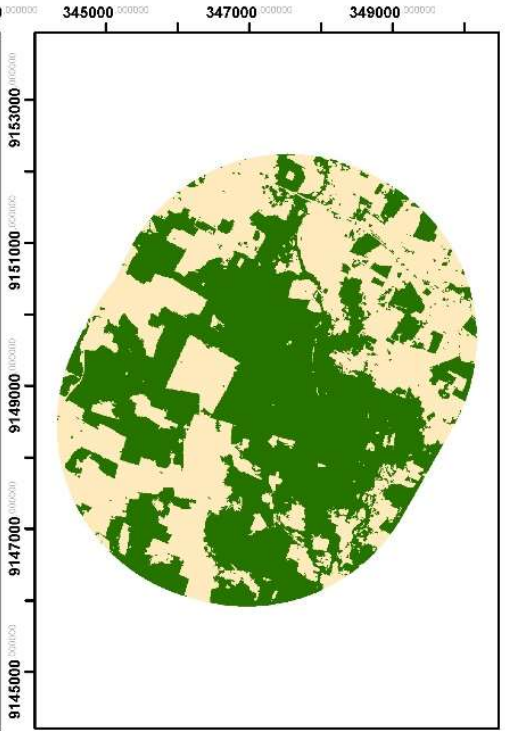

Área B3 - 2794,83 ha

Floresta - 1534,41 ha

Outros usos - 1260,42 ha

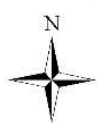

Figura 2. Mapa de uso e cobertura da terra das áreas inseridas no ambiente Baixada em áreas semiáridas no ano de 2014 Figure 2. Map of land use and land cover of the areas inserted in the Lowland environment in the semi-arid region in 2014.

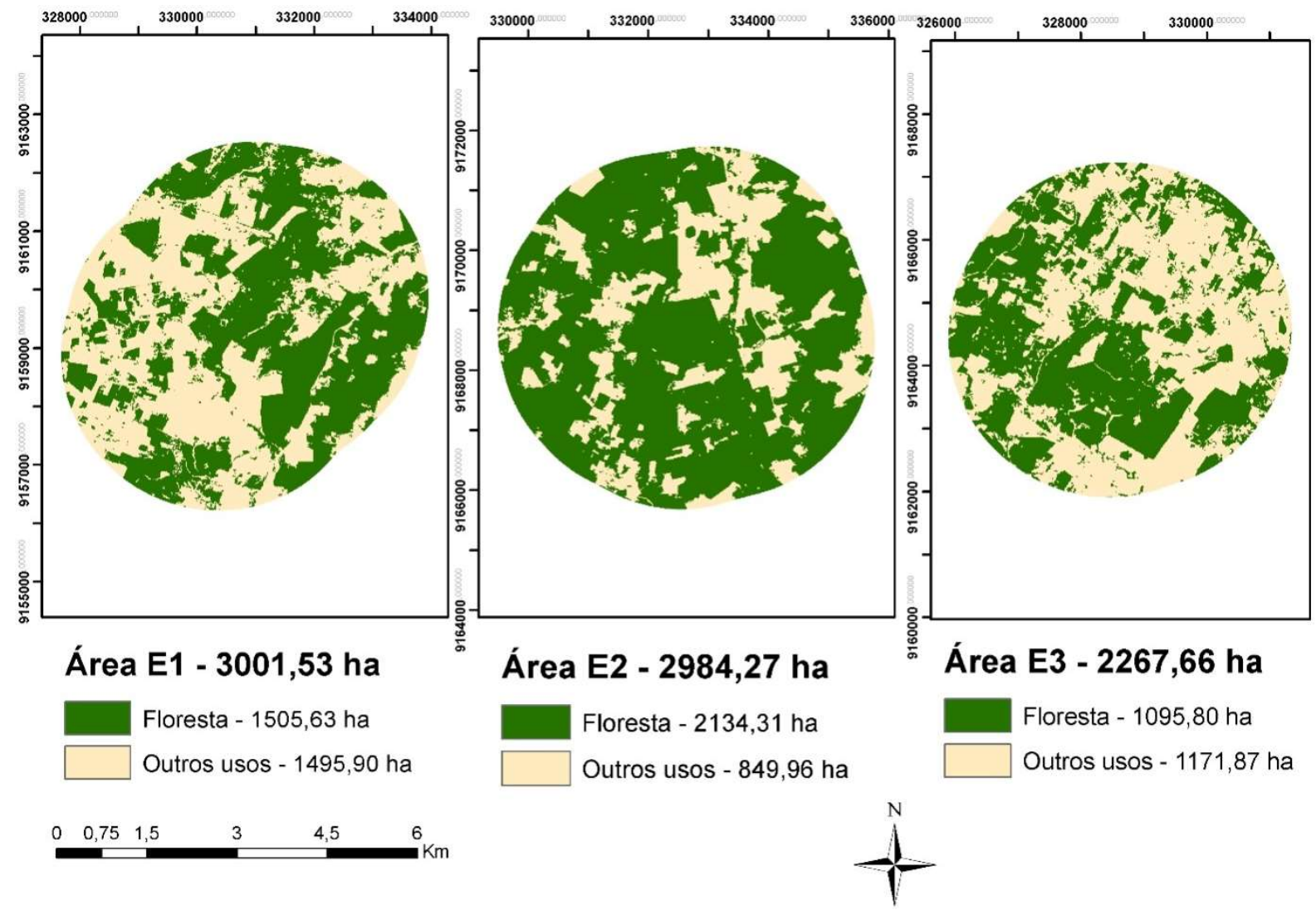

Figura 3. Mapa de uso e cobertura da terra das áreas inseridas no ambiente Encosta em áreas semiáridas no ano de 2014. Figure 3. Map of land use and land cover of the areas inserted in the Hill environment in the semi-arid region in 2014. 

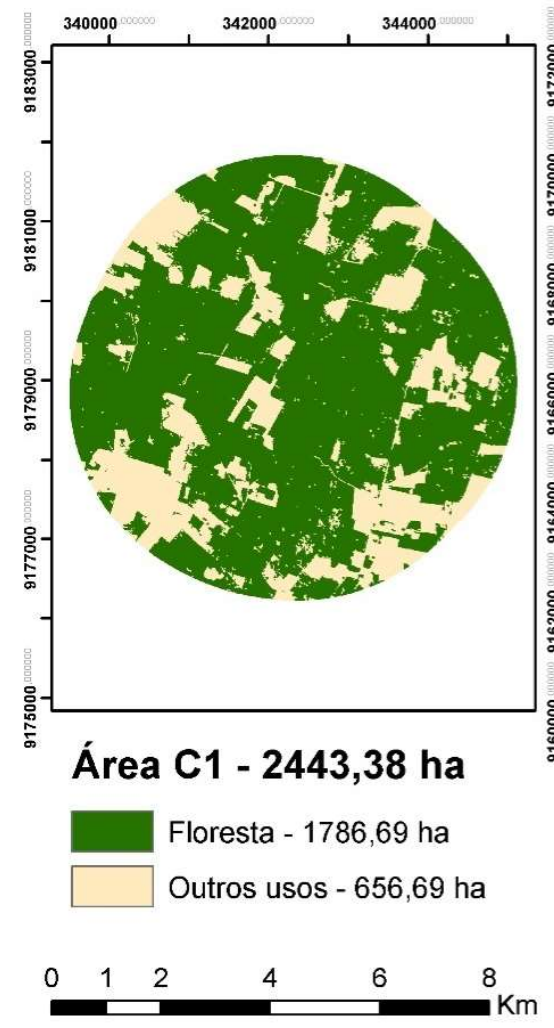
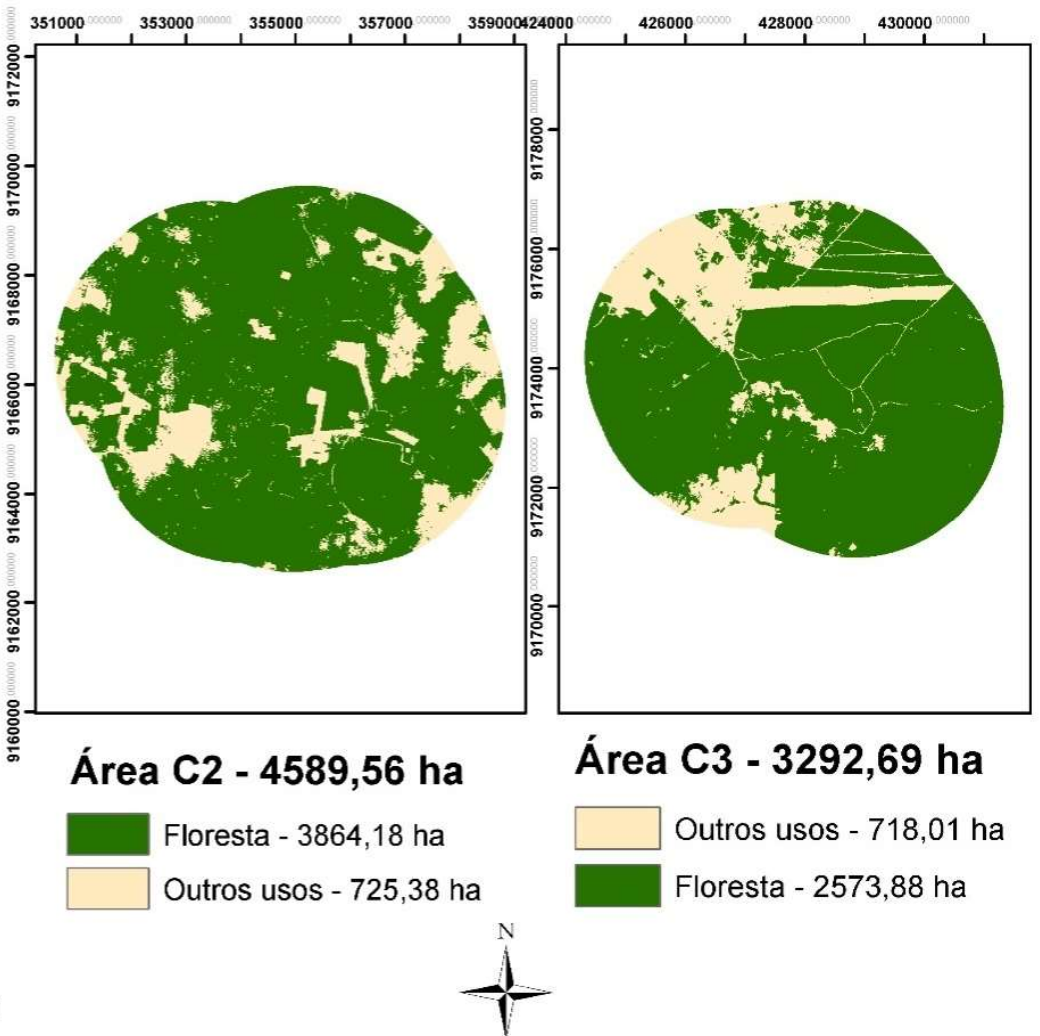

Figura 4. Mapa de uso e cobertura da terra das áreas inseridas no ambiente Chapada em áreas semiáridas no ano de 2014. Figure 4. Map of land use and land cover of the areas inserted in the Plateau environment in the semi-arid region in 2014.

Tabela 5. Valores dos parâmetros métricos selecionados para análise da paisagem das nove áreas inseridas em regiões semiáridas no Brasil. Table 5. Values of metric parameters selected for landscape analysis of nine areas inserted in semi-arid regions in Brazil.

\begin{tabular}{cccccccc}
\hline Ambiente & Área & Classe & NP & CA & PLAND & ENN_MN & ENN_CV \\
\hline \multirow{3}{*}{ Baixada } & B1 & Floresta & 278 & 1125,93 & 36,40 & 61,65 & 0,21 \\
& B2 & Floresta & 299 & 1329,06 & 50,61 & 33,98 & 0,37 \\
& B3 & Floresta & 247 & 1534,41 & 54,90 & 32,26 & 0,39 \\
\hline \multirow{3}{*}{ Encosta } & E1 & Floresta & 381 & 1505,63 & 50,16 & 28,02 & 0,45 \\
& E2 & Floresta & 109 & 2134,31 & 71,52 & 29,08 & 0,47 \\
& E3 & Floresta & 343 & 1095,80 & 48,32 & 27,99 & 0,46 \\
\hline \multirow{3}{*}{ Chapada } & C1 & Floresta & 74 & 1786,69 & 73,12 & 30,72 & 0,46 \\
& C2 & Floresta & 148 & 3864,18 & 84,19 & 21,57 & 0,51 \\
& C3 & Floresta & 152 & 2573,88 & 78,17 & 31,43 & 0,47 \\
\hline
\end{tabular}

CA: área total dos fragmentos; PLAND: porcentagem da paisagem; NP: número de fragmentos; ENN_MN: distância média do vizinho mais próximo; ENN_CV: coeficiente de variação da distância do vizinho mais próximo.

A transformação de áreas contínuas em um grande número de fragmentos isolados e de diferentes tamanhos é resultante do desmatamento das florestas. Nas áreas estudadas, após a supressão, o solo exposto é utilizado para cultivo agrícola e em períodos de secas a pecuária apoderasse da área tornando-se a principal atividade momentaneamente, e essa transformação promove diminuição de espécies e de populações, ocasionando um decréscimo na biodiversidade em escala local e regional.

Fernandes et al. (2017) analisaram paisagens inseridas em regiões semiáridas no Brasil e encontraram em sua pesquisa valores maiores que $80 \%$ para a classe de fragmentos menores que 5 (cinco) ha e diante desse resultado consideraram a paisagem estudada como fragmentada. Assim, respaldando os resultados dessa pesquisa.

A análise por classes de tamanho dos fragmentos, segundo Valente (2001), é um bom indicativo do grau de fragmentação, por ser função do número de fragmentos e da dimensão ocupada pelos hábitats. Entretanto, tem um valor interpretativo limitado por si só, por que não transmite informações sobre esse valor na paisagem (MCGARIGAL, 2015). Diante disso, analisou-se a métrica NP juntamente as métricas de área total da classe (CA) e a porcentagem na paisagem (PLAND), revelando que as áreas com alto NP detêm baixos valores de CA e PLAND. Assim, a área B1 no ambiente Baixada, as áreas E2 e E3 no ambiente Encosta e, a área C3 no ambiente Chapada são as áreas indicadas como as mais fragmentadas de cada ambiente.

No tocante ao ambiente Baixada, isso pode ser esclarecido pela alta presença de cultivos agrícolas e pastagem, além da exploração florestal desordenada. A diferença da área B1 para as outras áreas (B2 e B3) no ambiente Baixada, é devido à ausência de cursos d'água nessa paisagem e esse déficit hídrico atrelado as ações antrópicas dificultam o crescimento e desenvolvimento da vegetação nativa. Associado a esse fato, apresenta a maior distância média do vizinho mais próximo entre as três áreas do ambiente Baixada que foi de 61,65 metros e segundo Almeida (2008) esse valor para a métrica resulta em um médio isolamento entre os fragmentos. Em consequência, diminuição na capacidade de colonização de espécies em direção a outros fragmentos florestais, 
proporcionando perturbação na migração de genes entre populações de animais e vegetais.

Quanto as áreas do ambiente Encosta, o alto retalhamento ocorre pela presença de áreas urbanas no raio de estudo, agravando a conectividade entre as manchas, contribuindo para o encolhimento e aumento gradual da fragmentação dos remanescentes existentes, devido tanto a ampliação dos empreendimentos residenciais e industriais quanto à degradação pela poluição. Conforme Santos et al., (2008), o aumento da população humana interfere ainda na drenagem natural, impermeabilizando o solo, diminuindo a alimentação dos aquíferos e afetando no crescimento da cobertura florestal.

Todavia, as áreas do ambiente Encosta possuem menor isolamento entre as manchas com valores de 28,02 e 27,99 metros para as áreas E1 e E3, respectivamente, ao compará-las às áreas do ambiente Baixada. Embora, possua uma menor distância entre os fragmentos, essa situação perturba as populações vegetais que estão diretamente relacionadas ao grau de isolamento e para a persistência dessas populações é necessária maior conectividade entre as manchas.

No que diz respeito ao ambiente Chapada, as matrizes das três áreas do ambiente são de Floresta e em comparação aos outros ambientes, o ambiente Chapada apresenta uma redução na quantidade de fragmentos de floresta nativa com proporções menores. Apesar disso, a área C3, é considerada nesse ambiente como a mais fragmentada devido a existência da retirada de vegetação nativa por plano de manejo e verificase ainda que essa área é a que tem maior distância média do vizinho mais próximo entre as três áreas do ambiente Chapada com 31,43 metros.

Em relação aos parâmetros (NP, CA e PLAND), também foram analisados por Zanella (2011) para a Mata Atlântica e observou que a vegetação natural se encontra bastante fragmentada, pois apresenta maiores valores de NP e menores valores para as de CA e PLAND, sendo a pastagem a matriz nesse estudo.

Para todos os ambientes, atesta-se que o ambiente Chapada é o menos fragmentado, em razão da diminuição na quantidade de fragmentos em comparação aos outros ambientes, isso é a respeito do gradiente altitudinal, uma vez que se constata que em maiores altitudes há uma alta conectividade e, consequentemente, maior densidade de floresta. No ambiente Chapada, ocorre menor ação antrópica em atenção à atuação da fiscalização, visto que esse ambiente detém áreas com altitudes acima de 750 metros sendo considerado Áreas de Preservação Permanente (PERNAMBUCO, 1995).

A relação entre o número de fragmentos e área que ocupam é inversa, ou seja, os fragmentos da classe de tamanho pequeno (menores que cinco ha) apresentaram maior número de manchas e os efeitos nessa diminuição das áreas dos remanescentes promovem uma perda da diversidade de habitats (VIDOLIN et al., 2011). Além disso, os dados analisados das métricas nesses ambientes, comprovam que os fragmentos pequenos são imprescindíveis na paisagem e há uma importância do desempenho enquanto trampolins ecológicos (steppingstones), que são pequenas áreas dispersas pela matriz não florestal diminuindo o isolamento e facilitando que as espécies se locomovam pela paisagem, garantindo a continuidade do fluxo gênico, mantendo a variabilidade genética.

Em contrapartida, os fragmentos grandes, embora em menor número, apresentaram áreas significativas e foram responsáveis pela alta cobertura florestal em área, permitindo maior influência. Esse alto valor para a ocupação da paisagem por fragmentos maiores que 50 ha, nos ambientes Baixada e Encosta, é dado pela ligação entre fragmentos menores a partir da presença de Croton sp., espécie colonizadora. Já para o ambiente Chapada é explicada pela altitude e verifica-se que as áreas desse ambiente têm maior precipitação e isso pode intervir no desenvolvimento da vegetação. Ferraz et al. (2003), afirmam que no semiárido nordestino o aumento da altitude leva a uma redução na temperatura e, em consequência, aumento na precipitação e disponibilidade de água no solo, principal fator limitante da produtividade primária resultando em maior biomassa.

Diante disso, observa-se que existe uma alta possibilidade de recuperação dos ambientes, se houver interrupção da supressão florestal desordenada cambiando para práticas mais sustentáveis. Ademais, os resultados confirmam que as áreas dos ambientes consideradas como as mais fragmentadas (B1, E2 e E3 e C1) possuem alta quantidade de fragmentos pequenos e baixa em fragmentos de maiores extensões.

Esses parâmetros determinam que a paisagem nessas regiões semiáridas sofrem transformações em consequência ao clima que é bastante irregular com precipitações baixas e períodos de estiagem prolongados, o que pode exercer mais pressão na cobertura vegetal, agregado à extração de madeira, construção de moradias e/ou estradas, expansão agrícola e pecuária, prejudicando ainda mais as florestas nativas, o que pode resultar em fragmentos imersos em matrizes não florestais. As populações vegetais e animais inseridas nessas matrizes sofrem desequilíbrio, reduzindo o número de táxons especializados, porque grupos com baixa capacidade de dispersão são particularmente sensíveis à reduzir a conexão entre os fragmentos. Por isso, uma distância por menor que seja na paisagem pode ser um fator limitante para a movimentação de algumas espécies (METZGER et al., 2009).

\section{CONCLUSÕES}

O processo de fragmentação da vegetação nativa da região semiárida modifica-se em relação ao gradiente altitudinal, dado que quanto maior a altitude, menor é o grau de isolamento e, consequentemente, alta cobertura florestal.

Constatou-se, ainda que, o elevado número de pequenos fragmentos, indicados pelas métricas de área e isolamento, são imprescindíveis no aumento da conectividade entre os remanescentes. Para isso, aconselha-se promover aproximação desses fragmentos visando a formação de fragmentos maiores por meio de técnicas de manejo que favoreçam o estabelecimento da regeneração natural, e resultando em uma matriz florestal nessas áreas secas.

Assim, deve-se haver um planejamento da paisagem que constituirá na contribuição ecológica melhorando nas intervenções para a proteção à natureza, visando que haja câmbio da matriz não florestal. Além disso, a utilização de SIG no planejamento é uma importante ferramenta, pois apoia na tomada de decisão e no entendimento da real situação, combinando diferentes camadas de dados, facilitando ações sustentáveis nas regiões semiáridas.

\section{AGRADECIMENTOS}

À Fundação de Amparo à Ciência e Tecnologia de Pernambuco - FACEPE e ao Conselho Nacional de Desenvolvimento Científico e Tecnológico - CNPq pelo financiamento da pesquisa. 


\section{REFERÊNCIAS}

ALMEIDA, C. G. Análise espacial dos fragmentos florestais na área do Parque Nacional dos Campos Gerais, Paraná. 2008. 74f. Dissertação (Mestrado em Gestão do Território: Sociedade e Natureza) - Universidade Estadual de Ponta Grossa, Ponta Grossa, 2008

BRASIL MINISTÉRIO DO MEIO AMBIENTE. Programa de ação nacional de combate à desertificação e mitigação dos efeitos da seca. Brasília: Ministério do Meio Ambiente/Secretaria de Recursos Hídricos, 2004. $242 \mathrm{p}$.

COHEN, J. A coeficient of agreement for nominal scales. Educational and Measurement, Durham, v. 20, n. 1, p. 37-46, 1960.

DOI: https://dx.doi.org/10.1177/001316446002000104

ESRI. ArcGIS Desktop - ArcMap. Redlands: Environmental Systems Research Institute, 2014.

FERNANDES, M. R. M; MATRICARDI, E. A. T; ALMEIDA, A. Q; FERNANDES. M. M. Análise temporal da fragmentação florestal na região semiárida de Sergipe. Nativa, Sinop, v. 5, n. 6, p. 421-427, nov./dez. 2017. DOI: https://dx.doi.org/10.5935/2318-7670.v05n06a07

FERRAZ, L. C. L et al. Viabilidade de Sclerotinia sclerotiorum após a solarização do solo na presença de cobertura morta. Revista Fitopatologia Brasileira, Brasília, v. 28, n. 1, p. 17-26, 2003. DOI: http://dx.doi.org/10.1590/S0100-41582003000100003

LANDIS, J.; KOCH, G. G. The measurements of agreement for categorical data. Biometrics, Washington, v.33, n. 3, p. 159-179, $1977 . \quad$ DOI: https://dx.doi.org/10.2307/2529310

LOPES, H. L. Modelagem de parâmetros biofísicos para avaliação de risco à desertificação. 2005. 118f. Dissertação (Mestrado em Ciências Geodésicas e Tecnologia da Geoinformação) - Universidade Federal de Pernambuco, Recife, 2005.

MCGARIGAL, K. Fragstats: Fragstats help - versão 4.2. Computer software program produced by the author at the University of Massachusetts. Massachusetts: Amherst, 2015. 182 p. $\quad$ Disponível em: https://www.umass.edu/landeco/research/fragstats/docum ents/fragstats.help.4.2.pdf . Acesso em: 15 julho 2016.

MCGARIGAL, K.; MARKS, B. J. Fragstats: spatial pattern analysis program for quantifying landscape structure. Portland: Department of Agriculture/Forest Service/Pacific Northwest Research Station, 1995. 132p. DOI: https://dx.doi.org/10.2737/PNW-GTR-351
METZGER, J. P. et al. Time-lag in biological responses to landscape changes in a highly dynamic Atlantic forest region. Biological Conservation, Essex, 2009, v. 142, n. 6, p. 1166-1177. https://dx.doi.org/10.1016/j.biocon.2009.01.033

METZGER, J. P. O que é ecologia de paisagens? Biota Neotrópica, Campina, v. 1, n. 1, p. 1-9. 2001. DOI: http://dx.doi.org/10.1590/S1676-06032001000100006

MMA MINISTERIO DO MEIO AMBIENTE. SECRETARIA DE RECURSOS HÍDRICOS. Catálogo de imagens de satélite rapideye do ministério do meio ambiente. 2016. Disponível em: $<$ http://geocatalogo.mma.gov.br/>. Acessado em: $14 \mathrm{fev}$ 2016.

PERNAMBUCO (Estado). Lei ${ }^{\circ} 11.206$, de 31 de março de 1995. Dispõe sobre a Política Florestal do Estado de Pernambuco e dá outras providências.

SÁ, I. I. S. GALVÍNCIO, J. D.; MOURA, M. S. B. de; SÁ, I. B. Cobertura vegetal e uso da terra na Região Araripe Pernambucana. Revista Mercator, Fortaleza, v. 9, n. 19, p. $143-163,2010.2$ DOI: https://dx.doi.org/10.4215/RM2010.0919.0011

SANTOS, A. L. S; PEREIRA, E. C. G.; ANDRADE, L. H. C. Fragmentação florestal decorrente do uso do solo e do processo de degradação ambiental no município de Junqueiro (AL). Caminhos de Geografia, Uberlândia, v. 9, n. 25, p. 120-138, 2008.

SOUZA, C. G.; ZANELLA, L.; BORÉM, R. A. T.; CARVALHO, L. M. T. de; ALVES, H. M. R.; VOLPATO, M. M. L. Análise da fragmentação florestal da área de proteção ambiental Coqueiral, Coqueiral-MG. Revista Ciência Florestal, Santa Maria, v. 24, n. 3, p. 631-644, 2014. DOI: http://dx.doi.org/10.5902/1980509815743

VALENTE, R. O. A. Análise da estrutura da paisagem na bacia do rio Corumbataí, SP. 2001. 144f. Dissertação (Mestrado em Recursos Florestais). Universidade de São Paulo, Piracicaba, 2001.

VIDOLIN, G. P; BIONDI, D; WANDEMBRUCK, A. Análise da estrutura da paisagem de um remanescente de floresta com araucária, Paraná, Brasil. Revista Árvore, Viçosa, v. 35, n. 3, p. 515-525, 2011. DOI: http://dx.doi.org/10.1590/S0100-67622011000300014

ZANELLA, L. Análise da interferência antrópica na fragmentação da Mata Atlântica e modelos de simulação da paisagem na microrregião da Serra da Mantiqueira do Estado de Minas Gerais. 2011. $117 \mathrm{f}$. Dissertação (Mestrado em Ecologia Aplicada) Universidade de Lavras, Lavras, 2011. 